\title{
Study on Retinopathy And Microalbuminuria In Patients with Type 2 Diabetes Mellitus And Hypertension
}

\author{
Dr.Surender Mittal ${ }^{1}$, Dr. Shekhar Capoor ${ }^{2}$, Dr. G.N. Saxena ${ }^{3}$, Dr. Deepak Gupta ${ }^{4}$ \\ ${ }^{1}$ Senior Resident, Department Of Medicine, SMS Medical College, Jaipur \\ ${ }^{2}$ Assistant Professor, Department Of Medicine, MGUMST, Jaipur \\ ${ }^{3}$ Professor, Department Of Medicine, MGUMST, Jaipur \\ ${ }^{4}$ Associate Professor, Department Of Medicine, MGUMST, Jaipur
}

\begin{abstract}
Background: Retinopathy is a major cause of morbidity in India. Present study was undertaken to correlate retinopathy and microalbuminuria in patients with type 2 diabetes mellitus and hypertension.

Methodology: 100 patients of type 2 diabetes mellitus and hypertension fulfilling the inclusion criteria coming to OPD/Wards of MGUMST, Jaipur were recruited. They were subjected to detailed history (as per the performa), clinical and diagnostic examination. Data analysis was done using SPSS software.

Results: $63.6 \%$ of microalbuminuria cases in hypertension group, 50\% of microalbuminuria cases in diabetic group and $64.3 \%$ of microalbuminuria cases in combined group were associated with retinopathy.

Conclusion: There is a high prevalence and positive association between retinopathy and microalbuminuria in patients with type 2 diabetes mellitus and hypertension. We recommend screening for microalbuminuria in newly diagnosed hypertensive and diabetic patients to look for the presence of retinopathy in positive cases.
\end{abstract}

Keywords: retinopathy, hypertension, microalbuminuria, diabetes mellitus

\section{Introduction}

The multisystem complications of diabetes such as retinopathy, neuropathy,nephropathy and cardiovascular diseases are considered important, impinging on public health. Diabetic retinopathy is one of the leading causes of blindness worldwide; individuals with this condition run a 25 time higher risk of losing the sight than do normal individuals. Microalbuminuria is a well known predictor of poor renal outcomes in patients with type 2 diabetes mellitus and hypertension. At any level of eGFR it indicates chronic kidney disease and may reflect endothelial dysfunction in glomerular capillaries. It is now regarded as a marker of endothelial dysfunction. This study is intended to study the association between retinopathy and microalbuminuria in patients with type 2 diabetes mellitus and hypertension.

\section{Material And Methods}

The present study was conducted in Mahatma Gandhi University of Medical Sciences and Technology, Jaipur. The present study was a cross sectional study on 100 patients of Type 2 Diabetes Mellitus, Hypertension and a combined group i.e. Type 2 Diabetes Mellitus with Hypertension ; meeting inclusion and exclusion criteria as mentioned below.

\section{Inclusion criteria}

- Patients with type 2 diabetes mellitus.

- Patients with hypertension.

- Patients with both type 2 diabetes mellitus and hypertension.

\section{Exclusion Criteria:}

- History of MI / Angina

- Clinical evidence of heart failure

- Left bundle branch block

- Atrial fibrillation

- Febrile illness

- Urinary tract infection

- H/o drug intake like ACE/ARB's

- Acute poor metabolic control

- Smoking

- High serum calcium levels 
After applying above inclusion and exclusion criteria, the 100 patients were selected on the basis of simple random sampling method and detailed history and thorough clinical examination was done as indicated in the performa. The patients were subjected to Fundoscopy by Direct opthalmoscopy. NycoCard ${ }^{\mathrm{TM}} \mathrm{U}$-Albumin is a rapid in vitro test for measurement of low albumin concentrations in human urine.

\section{Results}

Table 1: Association of Retinopathy with Microalbuminuria

\begin{tabular}{|c|c|c|c|c|}
\hline \multirow{2}{*}{ Group } & \multirow{2}{*}{ Retinopathy } & \multicolumn{2}{|c|}{ Microalbuminuria } & \multirow[b]{2}{*}{ Total } \\
\hline & & Absent & Present & \\
\hline \multirow{3}{*}{ HTN } & Present & $\begin{array}{l}1 \\
(12.5 \%)\end{array}$ & $\begin{array}{l}14 \\
(63.6 \%)\end{array}$ & $\begin{array}{l}15 \\
(50 \%)\end{array}$ \\
\hline & Absent & $\begin{array}{l}7 \\
(87.5 \%) \\
\end{array}$ & $\begin{array}{l}8 \\
(36.4 \%) \\
\end{array}$ & $\begin{array}{l}15 \\
(50 \%)\end{array}$ \\
\hline & Total & $\begin{array}{l}8 \\
(100 \%)\end{array}$ & $\begin{array}{l}22 \\
(100 \%)\end{array}$ & $\begin{array}{l}30 \\
(100 \%)\end{array}$ \\
\hline \multicolumn{5}{|c|}{ Chi-square: 6.14, $p<0.05$} \\
\hline \multirow{3}{*}{ DM } & Present & $\begin{array}{l}3 \\
(18.7 \%)\end{array}$ & $\begin{array}{l}12 \\
(50 \%)\end{array}$ & $\begin{array}{l}15 \\
(37.5 \%)\end{array}$ \\
\hline & Absent & $\begin{array}{l}13 \\
(81.3 \%)\end{array}$ & $\begin{array}{l}12 \\
(50 \%)\end{array}$ & $\begin{array}{l}25 \\
(62.5 \%)\end{array}$ \\
\hline & Total & $\begin{array}{l}16 \\
(100 \%)\end{array}$ & $\begin{array}{l}24 \\
(100 \%) \\
\end{array}$ & $\begin{array}{l}40 \\
(100 \%)\end{array}$ \\
\hline \multicolumn{5}{|c|}{ Chi-square: 4.00, p < 0.05} \\
\hline \multirow{3}{*}{ DM+HTN } & Present & $\begin{array}{l}0 \\
(0 \%)\end{array}$ & $\begin{array}{l}18 \\
(64.3 \%)\end{array}$ & $\begin{array}{l}18 \\
(60 \%)\end{array}$ \\
\hline & Absent & $\begin{array}{l}2 \\
(100 \%)\end{array}$ & $\begin{array}{l}10 \\
(35.7 \%)\end{array}$ & $\begin{array}{l}12 \\
(40 \%)\end{array}$ \\
\hline & Total & $\begin{array}{l}2 \\
(100 \%)\end{array}$ & $\begin{array}{l}28 \\
(100 \%)\end{array}$ & $\begin{array}{l}30 \\
(100 \%)\end{array}$ \\
\hline
\end{tabular}

This table shows the association of retinopathy with microalbuminuria in three groups:

- Out of 22 cases of microalbuminuria 14 cases (63.6\%) had retinopathy in hypertension group which is statistically significant $(\mathrm{p}<0.05)$.

- Out of 24 cases of microalbuminuria 12 cases $(50 \%)$ had retinopathy in diabetes group which is statistically significant ( $\mathrm{p}<0.05)$.

- Out of 28 cases of microalbuminuria 18 cases (64.3\%) had retinopathy in combined (diabetes with hypertension) group which is statistically insignificant $(\mathrm{p}>0.05)$.

\section{Discussion}

This study was intended to study the association between retinopathy and microalbuminuria in patients with type 2 diabetes mellitus and hypertension. In our study, positive association is found between retinopathy and microalbuminuria in patients with type 2 diabetes mellitus and hypertension. In the present study, out of 24 patients of type 2 DM with microalbuminuria, $12(50 \%)$ patients had retinopathy while only $18.7 \%$ of normoalbuminuric cases had retinopathy $(\mathrm{p}<0.05)$. Thus, positive correlation was found between microalbuminuria and retinopathy which correlates well with other studies.

\begin{tabular}{|l|l|l|c|}
\hline Studies & $\begin{array}{l}\text { Year of } \\
\text { study }\end{array}$ & $\begin{array}{l}\text { Prevalence of retinopathy in } \\
\text { microalbuminuric patients in } \\
\text { Diabetes Mellitus }\end{array}$ & p value \\
\hline Masoud R Manaviat. et al (1) & $\mathbf{2 0 0 4}$ & $\mathbf{5 3 \%}$ & $\mathbf{0 . 0 0 1}$ \\
\hline Varghese A. et al (2) & $\mathbf{2 0 0 1}$ & $\mathbf{3 1 \%}$ & $<\mathbf{0 . 0 0 1}$ \\
\hline Present Study & & $\mathbf{5 0 \%}$ & $<\mathbf{0 . 0 5}$ \\
\hline
\end{tabular}

In our study out of 22 patients of HTN with microalbuminuria, 14 (63.33\%) patients had retinopathy while only $12.5 \%$ of normoalbuminuric had retinopathy $(<0.05)$. This correlates well with other studies.In a study by Gupta A. et al (2015), 85.7\% of patients with microalbuminuria had hypertensive retinopathy (3). In another study by

Busari OA.et al (2011), patients with microalbuminuria were more likely to have retinopathy than the patients without microalbuminuria ( $71 \%$ vs $37 \%$, $\mathrm{p}=0.001)(4)$.

Biensenbach. et al (1994) in their study had 85\% of patients with microalbuminuria having retinopathy (5). 
In the present study among the combined group of DM $+\mathrm{HTN}$, out of 28 patients of microalbuminuria, 18 patients $(64.3 \%)$ had retinopathy, while out of 2 patients of normoalbuminuria none had retinopathy. Though this is not statistically significant, but the $95 \%$ Confidence Interval indicates that association of microalbuminuria with retinopathy is considerably higher in this group. This might be due to the same pathogenic mechanisms for microvascular complications involved in causation of these conditions.

\section{Conclusion}

In our study we found that there was a high prevalence of retinopathy (as predicted by opthalmoscopy) and Diabetic Nephropathy (as predicted by microalbuminuria) in patients with type 2 diabetes mellitus and hypertension. Also, the prevalence increased with increase in duration and severity of the disease. This signifies that metabolic disturbances acts independently in causing these microvascular complications and when combined together have got synergistic effect. This implies that early diagnosis, timely and effective treatment can help in preventing these complications to some extent.We also found positive association between retinopathy and microalbuminuria in patients with type 2 diabetes mellitus and hypertension. We recommend screening for microalbuminuria in newly diagnosed hypertensive and diabetic patients and to look for the presence of retinopathy in positive cases. This will help in taking timely therapeutic measures to prevent any adverse event.

\section{Reference}

[1]. Manaviat M, Afkhami M, Shoja M. Retinopathy and microalbuminuria in type II diabetic patients BMC Ophthalmol.BMC Ophthalmology. 2004; 4(1):9.

[2]. Varghese A, Deepa R, Rema M, Mohan V. Prevalence of microalbuminuria in type 2 diabetes mellitus at a diabetes centre in southern India. Postgraduate Medical Journal. 2001; 77(908):399-402.

[3]. Gupta A, Pal A, Nelson S. Study of Microalbuminuria in Hypertension. International Journal of Scientific Study. 2015; 3(2):32-39.

[4]. Busari OA, Opadijo OG, Omotoso AB. Microalbuminuria and hypertensive retinopathy among newly diagnosed nondiabetic hypertensive adult Nigerians. Niger J Clin Pract.2011; 14:436-9.

[5]. Biensenbach G, Zazgornik J. High prevalence of hypertensive retinopathy and coronary artery disease in hypertensive patients with persistent microalbuminuria under short intensive therapy. Clin Nephrol.1994; 41:211-218. 